\title{
Quality Management of Aeronautical Surfaces Manufacturing
}

\author{
Srdjan Živković \\ Military Technical Institute Belgrade, Belgrade, Serbia
}

\begin{abstract}
Wind tunnel testing is experimental support of research and development during the design phase of aircraft and missile projects. The paper presents the developed method of manufacturing management by providing the required quality and accuracy of the wind tunnel models. The price of the wind tunnel model is several hundred thousand dollars and for this reason a manufacturing defect is not allowed. Additionally, any delays in the production process cause delay of testing in the wind tunnel. The costs of the delay are very high, because the wind tunnel laboratory is extremely expensive. All the foregoing is why the issue of the model's production is very important. Manufacturing of wind tunnel model within the contracted deadline and the required quality define tasks and objectives of production process management: identification of critical machining operations and activities; minimizing the time of coordinate inspections between cutting operations; identifying the main parameters of quality (shape, position in space, and angular relations); and material management for all other machining operations that follow. Specially developed methods of coordinate metrology are crucial for the management of the manufacturing process. Worldwide used specialized coordinate inspection programs have no option to measure the flaps deflection angles and wing dihedral angle. This paper introduces the originally developed coordinate inspection methods for determining the angular relations between lift and control surfaces. The methods presented in this paper have been confirmed in several international projects. The quality and accuracy of the models for wind tunnel testing are conditio sine qua non.
\end{abstract}

Keywords: wind tunnel models, manufacturing, coordinate metrology, quality management

\section{Introduction}

\section{Historical Background}

Design and manufacture of aircraft has many decades of tradition in Serbia, which dates back to before WWII. Military Technical Institute (MTI) was established after WWII as a national institution. Research and development in the field of aviation are a very important part of MTI. The Experimental Aerodynamics Laboratory was established in 1952. Its basic activities are model design and fabrication, wind tunnel testing, design and production of wind tunnel equipment, and instrumentation.

\section{General Remarks}

Wind tunnel tests are experimental support for the development and design of new aircraft or missile, used to verify the theoretical aerodynamics calculations. Models for wind tunnel tests are a special class of free-form

Srdjan Živković, Ph.D., Military Technical Institute, Experimental Aerodynamics Division, Prototype Production Department, Ratka Resanovića 1, Belgrade, Serbia.

Correspondence concerning this article should be addressed to Srdjan Živković, Military Technical Institute, Experimental Aerodynamics Division, Prototype Production Department, Ratka Resanovića 1, Belgrade 11030, Serbia. E-mail: srdjan.vti@gmail.com. 
surfaces. The assumption of similarity is the starting point for all experimental aerodynamics tests. The most important requirement is the geometric similarity between wind tunnel model and prototype airplane. Geometric similarity can be checked only by using specialized developed method of coordinate metrology (Joseph \& David, 1956).

According to ISO/TS 17450, all ideal features belong to one of the seven invariance classes: complex, prismatic, revolute, helical, cylindrical, planar, and spherical. Complex geometrical features have no invariance degree. Freeform surfaces, also called sculptured surfaces, may be classified as complex geometrical features. Freeform surfaces are widely used in the industry. The reasons for the implementation are functional and aesthetic: automotive and aerospace industries, household appliances, and others (Savio, De Chiffre, \& Schmitt, 2007).

Turbine blades and aircraft wings are defined using very different airfoils. In some cases, a very high accuracy of the aerodynamic surfaces was requested. The accuracy of airfoils (blades, impellers, wings, rudder, flaps, slats, aileron, and canards) has a very large impact on aerodynamic performance. Airfoil manufacturing errors have great impact on performance in the subsonic (Ichikawa, Kasai, \& Motogoe, 2008), transonic (Chen, Wang, \& $\mathrm{Hu}, 2011)$, and supersonic areas.

\section{Wind Tunnel Models Accuracy}

Size of wind tunnel test section dictates the size of the wind tunnel model. Most of the wind tunnel models are scaled in relation to the prototype aircraft. In rare cases, wind tunnel models are not scaled. Regardless of whether it is scaled or non-scaled, geometric accuracy of wind tunnel models is very high. A primary requirement for wind tunnel models is the high accuracy class. For wind tunnel models, two types of manufacturing tolerances are defined (Živković, 2011):

- Aerodynamic tolerances are related only to the aerodynamic performance of the aircraft model;

- Technical tolerances provide functionality and validity of all connections in the model and the carrier (sting).

The wind tunnel model is scaled, but aerodynamic tolerances are not obtained by simple scaling prototype airplane tolerances. Tolerances of wind tunnel models are much narrower. Inverse is also true: Prototype airplane tolerances are not a simple multiplication of wind tunnel model tolerances. They are much wider.

Aerodynamic tolerances of model shown in Figure 1 are a good explanation of prior consideration. For model whose wingspan is nearly $2 \mathrm{~m}$, aerodynamic tolerances are listed below (Živković, 2011):

- Overall length 1,593 $\pm 0.50 \mathrm{~mm}$;

- Fuselage profile $\pm 0.25 \mathrm{~mm}$;

- Wing span 1,940 $\pm 0.20 \mathrm{~mm}$;

- Wing root chord $358 \pm 0.10 \mathrm{~mm}$;

- Wing tip chord $215 \pm 0.10 \mathrm{~mm}$;

- Wing setting angle $+2^{\circ} \pm 0.10^{\circ}$;

- Wing dihedral angle $+3^{\circ} \pm 0.10^{\circ}$;

- Wing tip chord twisting $+3.5^{\circ} \pm 0.05^{\circ}$;

- Airfoil (NACA 632-415) form $\pm 0.05 \mathrm{~mm}$;

- Airfoil thickness $\pm 0.10 \mathrm{~mm}$;

- Wrp position $\pm 0.20 \mathrm{~mm}$;

- Tail-WRP angular relation $\pm 0.10^{\circ}$. 


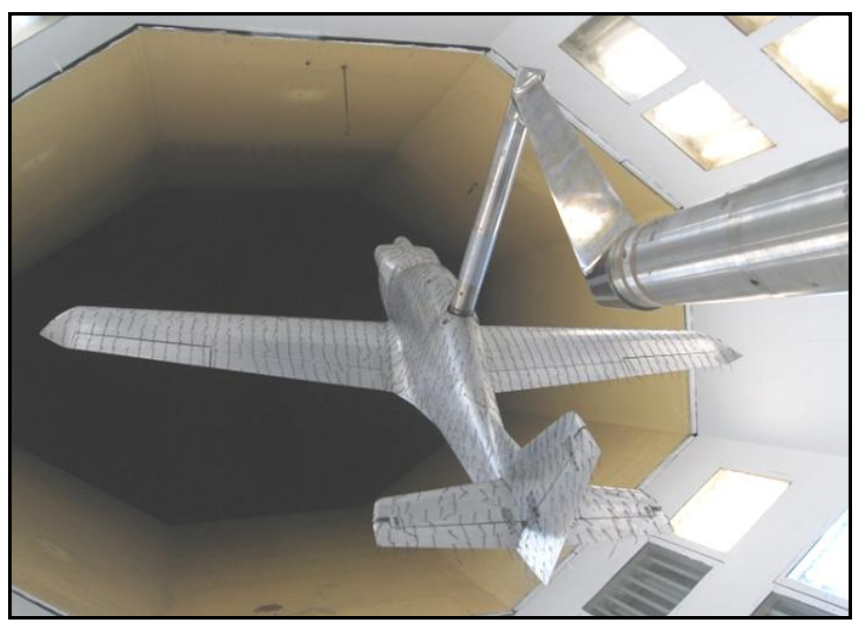

Figure 1. Model of airplane LASTA (scaled $1: 5$ ) in large subsonic wind tunnel T-35 (MTI Belgrade).

\section{The Manufacturing Accuracy in the World's Leading Companies}

Some of respectable world companies give web presentation manufacturing tolerances for wind tunnel models. Tolerances of aerodynamics surfaces for wind tunnel models in Russian CAGI (САGI = ЦАГИ Central Aero-hydrodynamics Institute) are $0.04 \mathrm{~mm}$. British ARA (Aircraft Research Association) declares accuracy for wind tunnel models are $\pm 0.025 \mathrm{~mm}$ "where required". Dutch NLR (Nationaal Luchten Ruimtevaart Laboratorium) declares form accuracy $<0.05 \mathrm{~mm}$ and angular accuracy $<0.1$ degree for wind tunnel models. German Deharde (Maschinenbau) declares "contour tolerance better than $\pm 0.015 \mathrm{~mm}$ " for wind tunnel models which they produce. French ONERA (Office National d'Etudes et de Recherches Aérospatiales) and NASA (National Aeronautics and Space Administration) are not declaring in public manufacturing accuracy of wind tunnel models. MTI (Military Technical Institute Belgrade) is only one company in Serbia that produces, for domestic purposes, models for wind tunnel testing. In recent years, MTI provides services of designing, manufacturing, and testing wind tunnel models for international projects. Manufacturing accuracy of the wind tunnel models shows that the MTI technological capabilities are very close to those of the above mentioned institutions.

\section{Aeronautical Surfaces Manufacturing}

Manufacturing a wing for wind tunnel models is the best way to explain complexity of production process aerodynamics surfaces. Wing is made of prismatic work piece by first shaped to their top view. Then alternate cutting upper and lower side of the wings to get more repeated operations required aerodynamic shapes. The required form must always be made in very narrow tolerances of shape. Among each of the cutting operations, it is necessary to measure the geometry of the wing.

Milling is a dynamic process and leaves the internal stresses in the machining part. These stresses are higher for larger depths of cut and lead to bending and warping of parts to be processed. Deformation leads to uneven supplements for the next machining operations. Unequal distribution of materials requires moving the machining reference plane in order to maintain maximum material condition.

The flow chart of the technological process wing manufacturing, namely, Figure 1, includes sequence inspection of geometry coordinate and flattening technological bases. These two sequences are repeated after each machining operation. Directions and the amount of displacement of reference plane in the machining 
process of aerodynamic parts can only be obtained by using the method of CMM (coordinate measuring machine) coordinate metrology. This is why the technological process cannot be planned and prepared in advance completely.

\section{Aeronautical Surfaces Machining Errors}

During manufacturing process of freeform surfaces that form models of aircraft lifting surfaces, there may be a few characteristic errors (Živković, 2013). Error analysis of the shape and position allows making corrections or changes to the technology chosen structure of the model and its lifting surfaces. The quality of the results is evaluated by analyzing the inspection accuracy of the measurement and evaluation of measurement errors.

Translation profiles in the direction perpendicular to the plane of suspension are shown in Figure 2. This error basically has several causes, but the most common is the wrong tool length compensation during initial setting by the $\mathrm{CNC}$ (computer numerical control) operator.

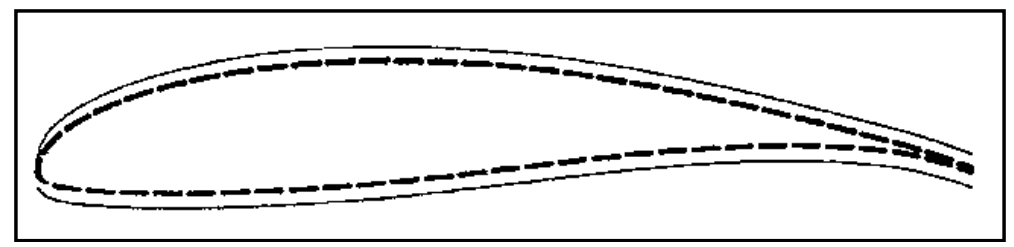

Figure 2. Manufacturing error; translated airfoil.

The second important cause of airfoil translation is the thermal deformation of machine tools. Error occurs, if the upper side of airfoil is made in a thermal balance and the opposite side in the second. A typical situation occurs, when the processing is completed in one working day and machine has reached operating temperature. Machining opposite side begins with the second work day and cold machine leads to deviations although the machine operator to comply with all the activities required conversion.

Translation profiles in the direction parallel to the plane of the suspension. This error occurs in the incorrect setting of the machining coordinate system of the work piece. It manifests itself as an upper profile translated in relation to the lower profile. In these cases, the piece usually rejected. Very rarely, only if it occurs in the earliest stages of manufacturing, can this error be improved. One of the basic parameters of the airfoil leading edge radius becomes undercut. The most common cause is insufficient experience of the operator on CNC milling machine.

According to the profiles in sections at equidistant from the theoretical form, the same variation occurs in the upper and lower surfaces shown in Figure 3. Error occurs in five-axis milling machine, when the cutter is constantly perpendicular to the surface to be processed. It occurs due to the mismatch point of rotation defined by postprocessor (pivot point) and the same settings on the five-axis milling machine. These errors are easily corrected. It is necessary to repeat previous machining operation.

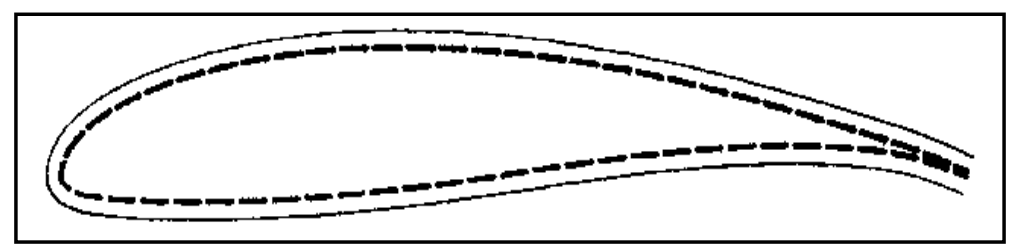

Figure 3. Manufacturing error; equidistance airfoil. 
Another cause is the difference between nominal measures of cutter (ball-end) and used during generating the tool path. It occurs due to re-sharpening cylindrical cutter with ball end. This avoids the use of cutters with taper cut and spherical end. Sharpening of cutting tools leads to the shortening them, but nominal measures are not changes.

Twisted airfoils (profiles) in successive sections rotated in relation one to each other, as shown in Figure 4. This error almost always occurs in manufacturing of lifting and control surfaces. Several elements influence the occurrence of these errors: chosen materials, chosen technology process, cutter with low wear resistance, and non-sharp cutter. The main cause is the residual stresses in the work piece after machining operations.

The waves of surfaces are the results of vibration and wear of cutting tool, as shown in Figure 5. Eliminating these errors requires using very sharpen carbide cutting tools. In reality (Figure 5), the total error is a combination of all previously described errors (Majstorović \& Živković, 2013).

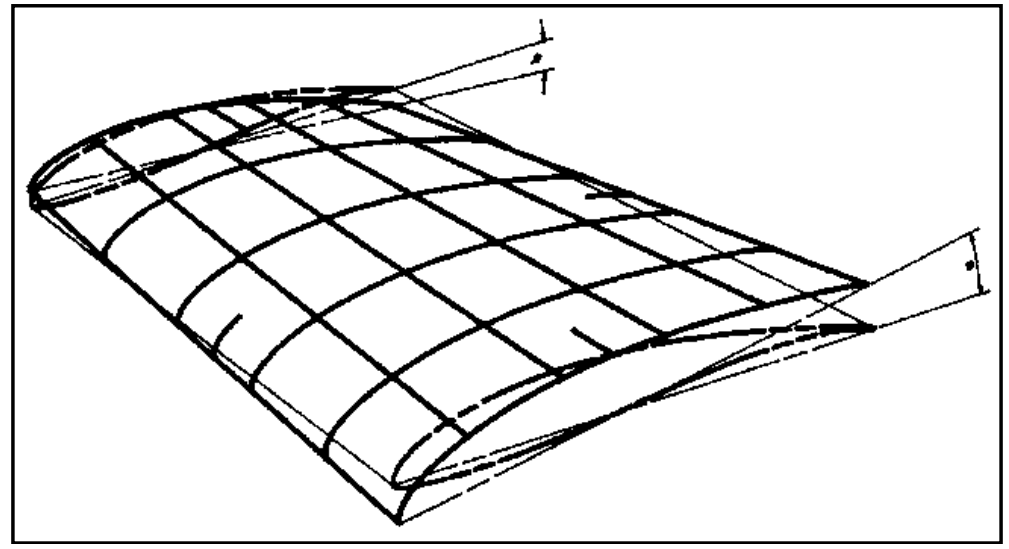

Figure 4. Manufacturing error; twisted airfoils.

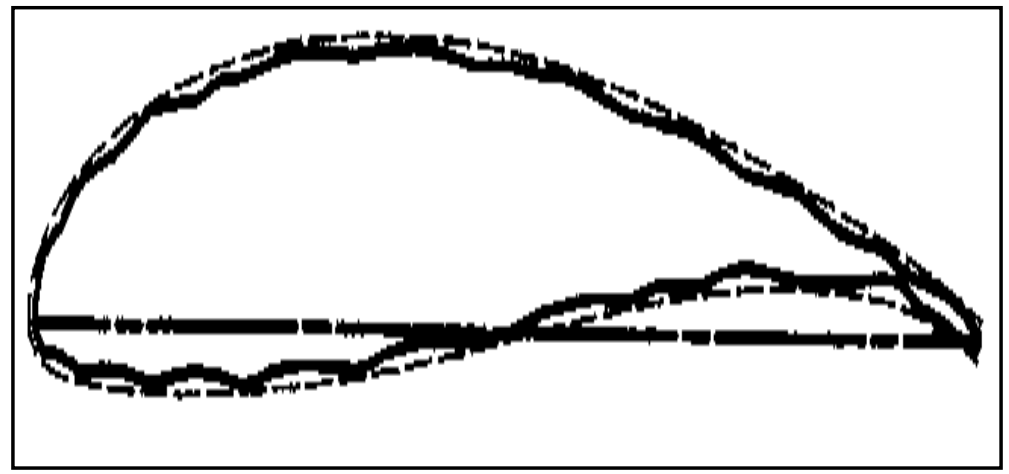

Figure 5. Manufacturing error; the wear of cutting tool.

\section{Related Works}

The fact is that small number of countries in the world performs wind tunnel tests and produce models for testing. Papers on this topic are rare. Acquired experimental knowledge in world leading companies very often is not available in the public. In this chapter, published papers are analyzed.

On personal model aeronautics pages, Hepperle (2014) presented aerodynamics of model aircraft. Airfoil MH32 was measured on the coordinate measuring machine, after a significant difference between the calculations and tests in the wind tunnel has been noted - the wind tunnel results showed increasing drag when 
the lift coefficient fell below 0.25 approximately. He concluded that the manufacturing deviations of MH32 airfoil are already quite large for a typical model using this airfoil and very much for a wind tunnel model. He could save money and time that the airfoils measured on CMM prior to testing in the wind tunnel.

Report described 2D measurements on the NACA 63-415 airfoil and modified NACA 63-415 airfoil (Bak, Fuglsang, Johansen, \& Ioannis, 2000). The same airfoil was used in the design of aircraft wing model (see Figure 1). Chapter four of this report provides a diagram of variations of only one cross-section between the theoretical and the measured co-ordinates, without any analysis. Only one sentence is stated-only minor differences were found between the theoretical and the measured co-ordinates. For a $1.9 \mathrm{~m}$ wing span and 0.6 $m$ chord length, measurement of only one section is insufficient for any conclusions.

The test results of over 100 different airfoils are presented in three volumes: volume 1 (Selig, Guglielmo, Broeren, \& Giguere, 1995), volume 2 (Selig, Lyon, Giguere, Ninham, \& Guglielmo, 1996), and volume 3 (Lyon, Broeren, Giguere, Gopalarathnam, \& Selig, 1997). All wind-tunnel models have a nominal $304.8 \mathrm{~mm}$ chord length and $854 \mathrm{~mm}$ wing span. All the wind tunnel models are measured on CMM to determine the actual airfoil shape. The measurements were performed only on a single section. The upper and lower surfaces of the wings have been measured at 40 points each. Deviations of some airfoils are significantly greater than specified tolerance. The authors noted that if the variances between the measured and theoretical airfoils are larger than tolerance $0.254 \mathrm{~mm}$, the wind-tunnel data may not be an accurate representation of the true airfoil performance.

Optical methods significantly reduce inspection time compared to CMM with contact probes. Optical measurement system based on photogrammetry is presented in the paper by Zilker and Winter (1999). Inspection system, simply called "WinGS" (wing geometry sensor), consists of two CCIR (Comite Consultatif International des Radio Communications) video cameras and a fringe projector with a halogen lamp. System is a great help to the worker during the final polishing by sand paper.

Presented optical system in the paper by Buck (2000) is very similar to the previous one. This optical system projects various fringe patterns onto the wind tunnel model surface. Deviations from CAD (computer aided design) geometry are shown in gray-color gradients over the whole wind tunnel model.

Optical measurements wind tunnel models using laser scanning method are presented in the paper by Buck et al. (2006). This inspection system uses triangulation technique to determine the coordinate position of points on the wind tunnel models surfaces. The CMM, with a touch trigger probe, is used only for positioning reference points over the wind tunnel model surfaces. All scanned data are exported as an electronic 3D point cloud and compared with CAD file. Differences between actual and designed geometry are presented by colors on the wind tunnel model and scale on the computer screen. Measured geometry could be a good basis for advanced calculation. It is necessary to distinguish form deviation and position deviation.

Comparative analysis of two optical systems by airfoil measuring in the laboratory condition, geodetic tachometer, and photogrammetry, is presented in the paper by Bručas and Sužiedelyt-Visockien (2010). Wing segment was measured as an object of unknown geometry. CAD files obtained by reverse engineering were compared. Authors have presented the advantages and disadvantages of both systems: price, speed, environmental condition dependence, points cloud density, and accuracy. This excellent analysis would be complemented with a comparison with the native CAD.

Uncertainty of the position and orientation of large scale aircraft assembly (wing-fuselage) was considered in the paper by Chen, Du, and Tang (2013). Although considered objects of large dimensions are compared to 
models for wind tunnel testing, the developed methodology can be applied to this class of aerodynamic surfaces. The starting point is a previously defined KMC (key measurement characteristics) concept. According to KMC, the assembly datum is defined as a set of geometrical features with optical target points (OTP). In the simulation model, the position and orientation of the wing-fuselage are determined by measuring OTP. The developed mathematical model was applied over the set of measured coordinates of OTP.

Combination of optical and contact measurement method was presented in the paper by Boon, Dwight, Sterenborg, and Bijl (2012). Combining overcomes the disadvantages of both methods. The wing model defined with DU96-W-180 airfoil was measured in seven sections with the CMM. CMM measurements of the airfoil provide high accuracy in the chord direction and low accuracy in the cross direction. In the next step, the upper and lower surfaces of the wing were measured by optical method based on photogrammetry. The result is points-cloud with measured 3D coordinates of the wing model. These two sets of measured coordinates are combined using the Bayesian methods. The resulting 3D model represents the measured wing using two different techniques. The result is redesigned wing compared to the original CAD model.

\section{Advanced Approach}

Previously analyzed papers do not distinguish "form deviations" and "position deviations". To make the results of the measurements correct, these deviations should be separated, for example, if wing semi-span is $1,000 \mathrm{~mm}$ and allowed dihedral angle deviation $0.1^{\circ}$, position deviation of wing tip is $1.745 \mathrm{~mm}$. This value greatly exceeds the form tolerance of $\pm 0.05 \mathrm{~mm}$. Completely mistaken conclusions are possible.

Any deviation beyond a defined angular tolerance for dihedral angle and wing setting angle greatly affects the results of wind tunnel testing. Flaps and ailerons deflection angles cannot be measured by previously analyzed methods. Paper of Chen et al. (2013) considers uncertainty of the wing position, but only by measurement the upper side of the wing.

In order to determine the position of the wing in the space, it is necessary to measure the upper and the lower sides of the wing. The measurement result is the WRP (wing reference plane) that accurately defines the position of the wings in the space. For this purpose, an original mathematical model was developed, based on the paradigm of coordinate metrology shown in Figure 6.

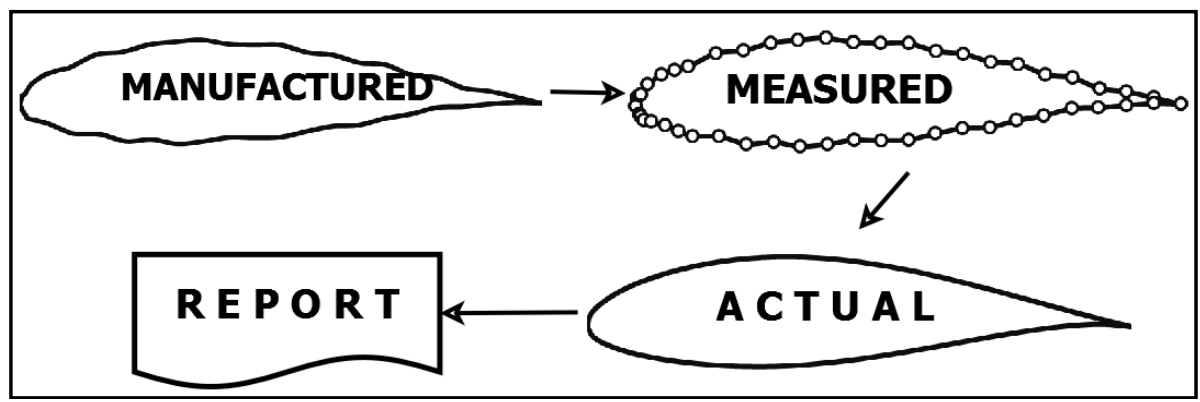

Figure 6. Paradigm of airfoil metrology.

Metrology identifications of complex mechanical parts are based on the following paradigm (Majstorović $\&$ Hodolič, 1998): Parts are manufactured (real shape) according to CAD model $\rightarrow$ Measuring points are obtained using coordinate measuring machine on real geometry $\rightarrow$ Actual geometry is calculated applying the same mathematical definition of geometry on measured points $\rightarrow$ Report is generated as differences between 
nominal geometry (theoretical, obtained from CAD) and actual geometry (measured, obtained from CMM). Coordinate metrology of WRP is based on that paradigm shown in Figure 6.

\section{Airfoil and Wing Geometric Definitions}

\section{Airfoil Terminology}

The shape of a wing or blade (of a propeller, rotor, or turbine) or sail as seen in cross section is called airfoil (aerofoil). Body shaped by airfoils causes aerodynamic forces lift and drag. The lift on an airfoil is primarily the result of its angle of attack and shape.

Airfoils are defined in tables and classified using four and five digits. Upper and lower sides of the airfoil are defined by the control points for the range of 0 to 100\%, as shown in Figure 7.

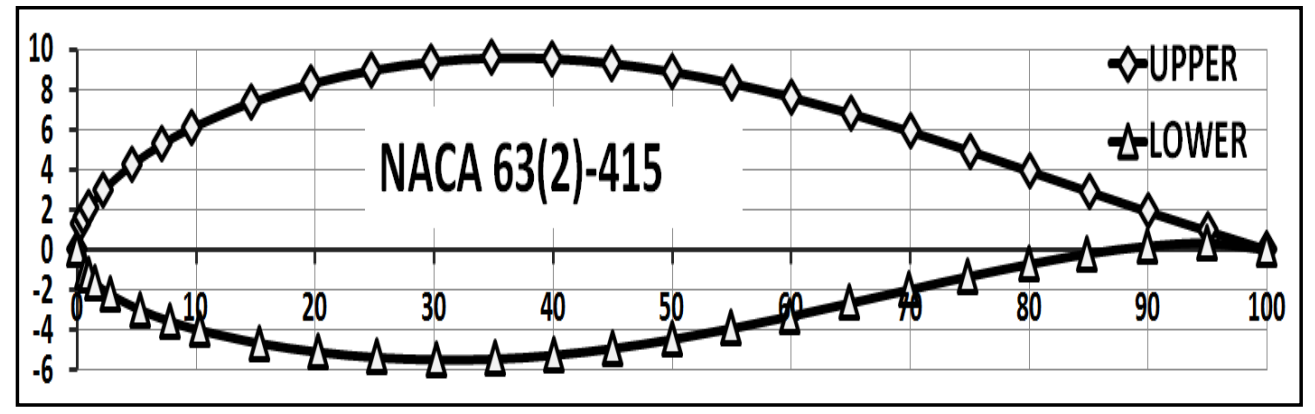

Figure 7. NACA $63_{2}-415$; airfoil definition points.

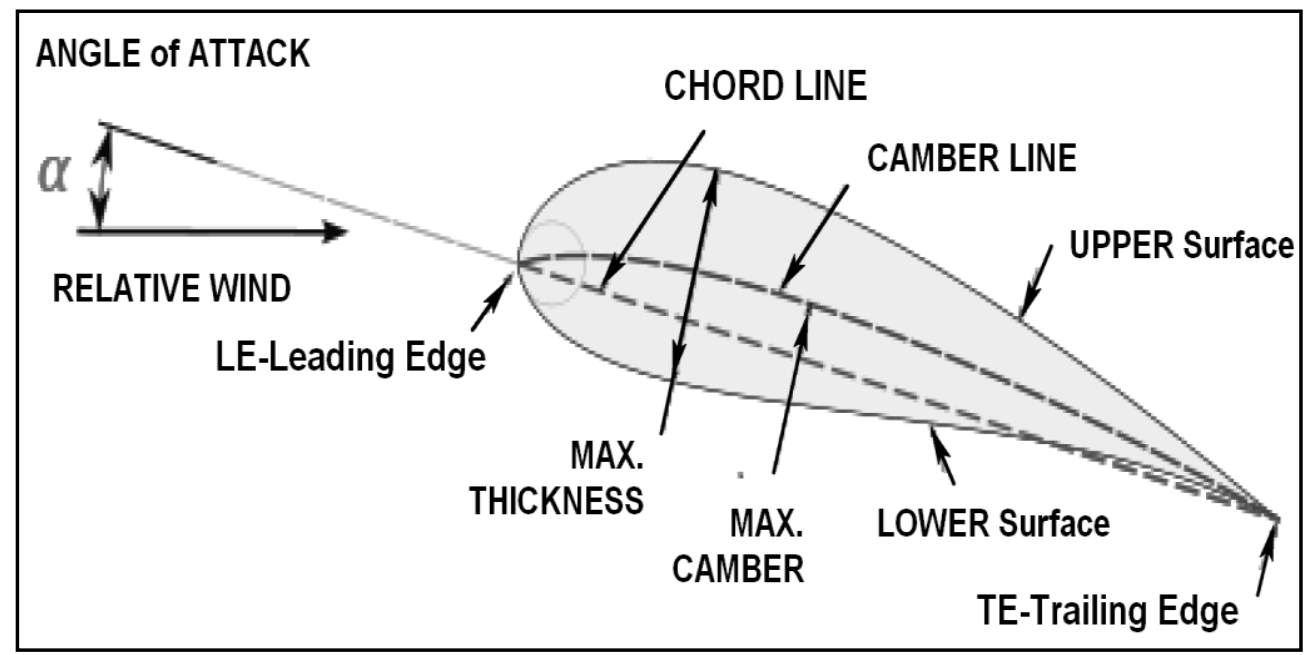

Figure 8. Airfoil nomenclature.

The various terms are related to airfoils, as shown in Figure 8. Upper surface is generally associated with higher velocity and lower static pressure (Abbott \& Von Doenhoff, 1959). Lower surface has a comparatively higher static pressure than the suction surface. The pressure gradient between the two surfaces contributes to the lift force generated for an airfoil. The leading edge (LE) is the point at the front of the airfoil that has maximum curvature. The trailing edge (TE) is at the rear of the airfoil. The chord line is a straight line connecting the LE and TE of the airfoil. The chord length (or just chord) is the length of the chord line and is the characteristic dimension of the airfoil section. The mean camber line is the locus of points midway between the upper and lower surfaces. The thickness of an airfoil varies along the chord. It may be measured in either of 
perpendicular to the camber line or measured perpendicular to the chord. The aerodynamic center, which is the chordwise length about which the pitching moment, is independent of the lift coefficient and the angle of attack. The center of pressure, which is the chordwise location about the pitching moment, is zero.

\section{Wing Position in Space}

The shape of the wing, when viewed from above looking down onto the wing, is called a plan form. For a rectangular wing, the chord length at every location along the span is the same. For most other plan forms, the chord length varies along the span.

Each airfoil is in the plane perpendicular to the WRP scaled chord to the fixed length. If any of the airfoil is rotated, it is named "geometric twisting" of a wing. If you change the type of airfoil along the wing span, it is named "aerodynamic twisting" of a wing (Rendulić, 1962).

Transformation matrix exactly defines the position of the wings in airplane (absolute) coordinate system. Components of the normal vector of the WRP give information about setting and dihedral angle, as shown in Figure 9.

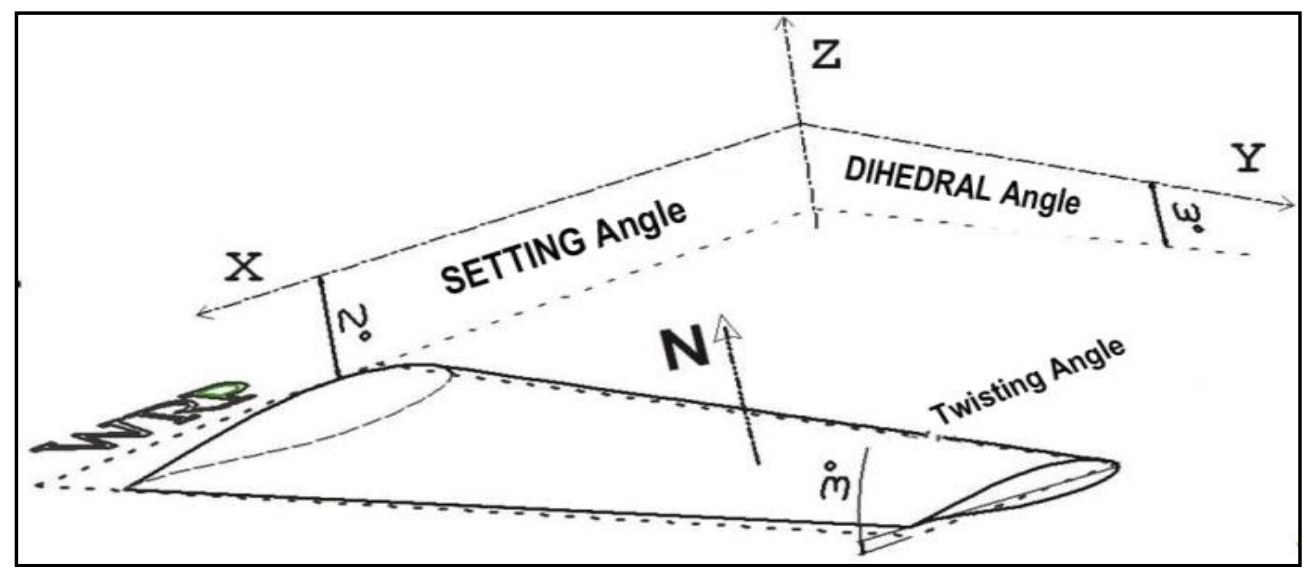

Figure 9. Wing position in space (airplane LASTA).

Table 1

WRP Transformation Matrix (Wind Tunnel Model, Scaled 1: 5, Airplane LASTA)

\begin{tabular}{|l|l|l|l|}
\hline \multicolumn{2}{|l|}{ X } & Y & \multicolumn{2}{l|}{} \\
\hline & WRP origin translation $(\mathrm{mm})$ & \multicolumn{2}{l|}{} \\
\hline & 565 & 0 & -104 \\
\hline & WRP axis rotations & 0.001826 & 0.034852 \\
\hline $\mathrm{I}$ & 0.999391 & 0.998630 & -0.052336 \\
\hline $\mathrm{J}$ & 0.000000 & 0.052304 & 0.998021 \\
\hline K & -0.034899 &
\end{tabular}

A typical example of a transformation matrix is shown in Table 1. The data in the table refer to the aircraft LASTA (swallow) wing which is designed by MTI Belgrade. Component I of the normal vector along the X axis gives the value of the wing setting angle $\left(\mathrm{ACos} 0.999391=2^{\circ}\right.$ ). Component $\mathrm{J}$ of the normal vector along the $\mathrm{Y}$ axis gives the value of the wing dihedral angle $\left(\mathrm{ACos} 0.998630=3^{\circ}\right)$. Figure 9 shows aircraft LASTA wing position in space.

Aerodynamic calculations made by principal project request data provide the basic airworthiness characteristic of prototype airplane. 


\section{Measuring Angular Relationships of Aerodynamic Surfaces}

Angle is semi-space between two planes or two lines. The angle between two planes is the angle between the vectors of their normal. Apparently it seems impossible to determine the angular relationship between two elements of free-form surfaces.

Angular relationships of lift and control surfaces, wings, and all the elements need to determine the model for wind tunnel testing and are essential to the quality of the final assembly. In relation to the measurement of airfoil shape deviation from this determination, it is complicated and requires complex mathematical models and calculation (Živković, 2011). It is necessary to find the plane that represents the wing and calculates the required angular relationships, such as the wing setting angle and the dihedral angle.

The plane which represents the position of the wings in space is WRP. This plane is not material and its direct measurement is impossible. Modelling of airplane wings in the CAD/CAM system begins by defining the WRP. Absolute coordinate system is the basis for positioning the wings and the other entire element in model space.

Figure 10 shows a flow chart of WRP measurement. For easier consideration of the whole complicated measurement process, the flowchart has equation and the corresponding figures.

WRP measuring is based on well-known equations of analytical geometry, obtained by dividing the line segment in a given ratio (Faux \& Pratt, 1979). Coordinate of points $w_{T i}$ (see Figure 10), which divides a line segment $U L$ (position vectors $u_{T i}$ and $l_{T i}$ ) in given ratio $\lambda$, is calculated according to vector equation (1):

$$
w_{T i}=\frac{u_{T i}-\lambda_{i} \times l_{T i}}{1-\lambda_{i}} ;(i=1 \ldots n)
$$

Dividing parameter $\lambda$ is defined by equation (2):

$$
\lambda_{i}=-\frac{\left|u_{i} w_{i}\right|}{\left|l_{i} w_{i}\right|}=-\frac{m_{i}}{n_{i}} ;(i=1 \ldots n)
$$

In specific case, $\lambda=-1$, equation (1) gives a coordinate of midpoints of equation (3). For symmetric and non-twisted airfoil, dividing parameter is always $\lambda=-1$. Calculation of WRP is simplified (Majstorović \& Živković, 2013); the theoretical and measured points also are arithmetic midpoints, vector equation (3):

$$
w_{M i}=\frac{u_{M i}+l_{M i}}{2} ;(i=1 \ldots n)
$$

In accordance to paradigm of coordinate metrology, the measured coordinates of WRP can be obtained by applying vector equation (4):

$$
w_{M i}=\frac{u_{M i}-\lambda_{i} \times l_{M i}}{1-\lambda_{i}} ;(i=1 \ldots n)
$$

Equations (1) and (4) are applied to the same set of points (Majstorović \& Živković, 2013): equation (1) on the set of the theoretical coordinates obtained from CAD—index $T$ and equation (4) on the set of the measured coordinates, obtained from CMM-index $M$.

The essence of this approach is the following: Errors (form deviations) due to machining are small compared to the dimensions of the wing. If the paradigm of coordinate metrology is applied to all geometric features (prismatic, revolute, helical, cylindrical, planar, and spherical), then it could be applied to free-form feature. This is the reason for applying the same set of equations for theoretical and for measured coordinates. 


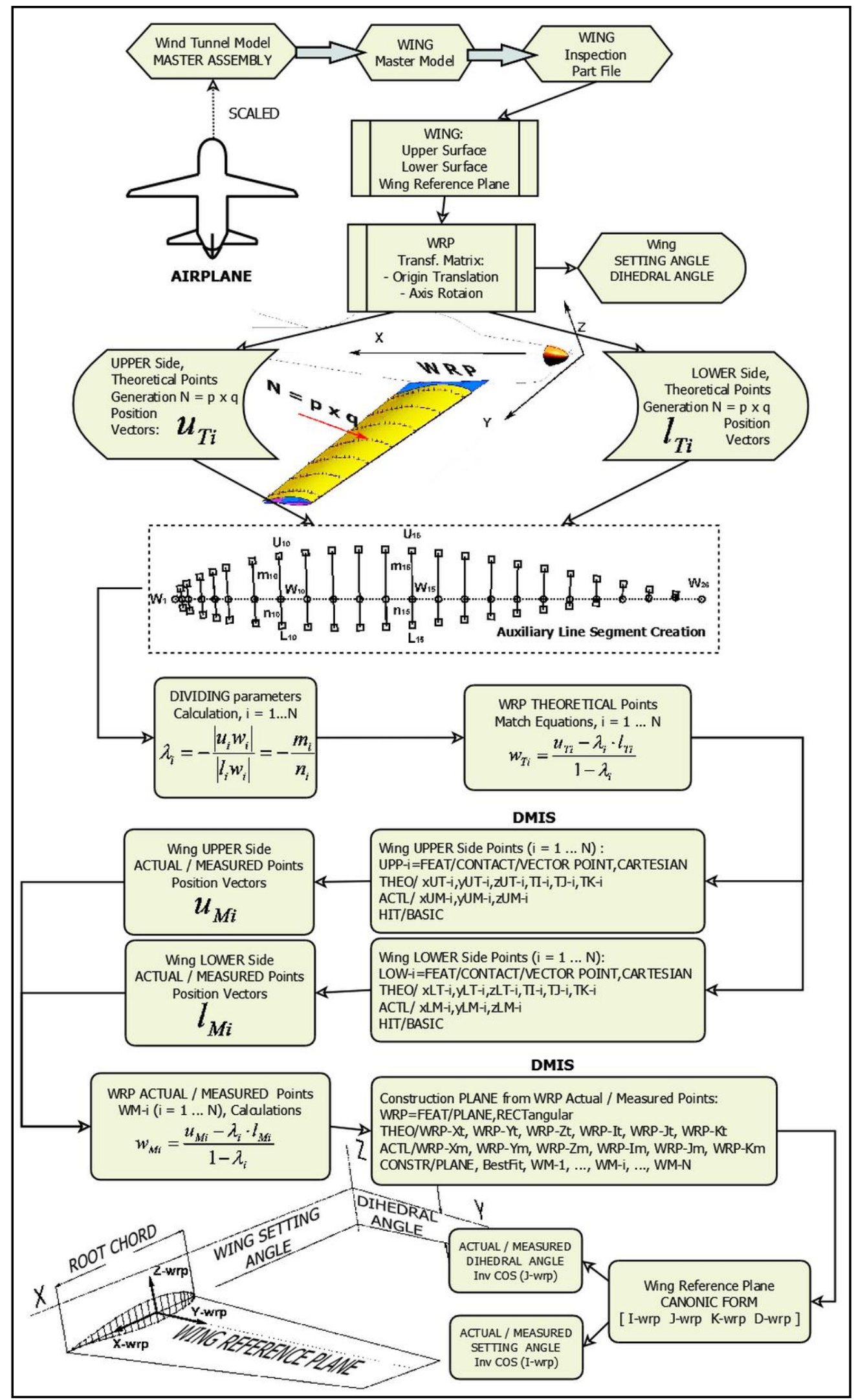

Figure 10. Flow chart of wing reference plane measurement. 


\section{Management of Wing Manufacturing Process}

Inspection of the geometry element model for wind tunnel testing of aircraft and missiles carries many characteristics in relation to other classes of objects defined by free-form surfaces. It is primarily caused by the shape, configuration, and design solutions. Aircraft has a central plane of symmetry and the parts that form the lift and control surfaces are roughly shaped plate. Besides the shape, main interest is their relationships in a space.

The accuracy required in the wings, fin, horizontal and vertical tail, canards, ailerons, flaps, and slats is still several times more stringent than the required accuracy of the fuselage. Very often, tolerances of airfoil leading edge are narrower than the trailing edge zone.

\section{Critical Manufacturing Operations}

Geometry inspection is the key of quality management of whole manufacturing process, as shown in Figure 11. It is most important results of the final geometric inspections of the models assembly and the total time of manufacturing. In optimization of coordinate inspection activities, it is necessary to execute comprehensively (Živković, 2011). It is necessary to cover the preparations and execution time of metrological task.

Minimizing the time coordinate inspection shall not affect the measurement accuracy and reliability of the results. It is necessary to achieve the projected quality of the completed model aircraft in the shortest possible time interval for the current technical-technological equipment. Total time and final quality are inextricably linked wind tunnel model categories.

Producing the wind tunnel models, according to the required (designed) quality and within the total time, defined mission and goals of management of the manufacturing process wind tunnel models:

- defining the flow chart of manufacturing process; identifying critical operations and activities;

- minimizing the time coordinate inspections of model elements among machining operations;

- providing management of the additional machining material for all types of machining operations as follow;

- defining methods for identifying quality parameters related to the spatial position and the mutual relations of the elements of the wind tunnel models.

Number of machining operations on most affects the overall execution time. Elements of the wind tunnel models are made by milling on machines with three-five axis simultaneous control. Configuration of the aerodynamic surfaces requires that the number of machining operations reduced to the least possible number. A number of the machining, with smaller depths of cut, eliminate residual stresses in the part processed but multiplied many times already making great time. A smaller number of operations with greater depths of cut drastically shorten the overall production time, but as a result of residual stresses. Residual stresses deform the aerodynamics part and have a great influence on the geometric accuracy.

Reducing the time of machining of individual operations is directly linked to the installed power machine tools, the spindle speed maximum, and wears resistance of cutting tools.

The preliminary-final time related to the activities performed on the machine tool but not a direct machine processing. These activities include preparation of cutting tools and machinery, installation, alignment, and clamping of parts. 


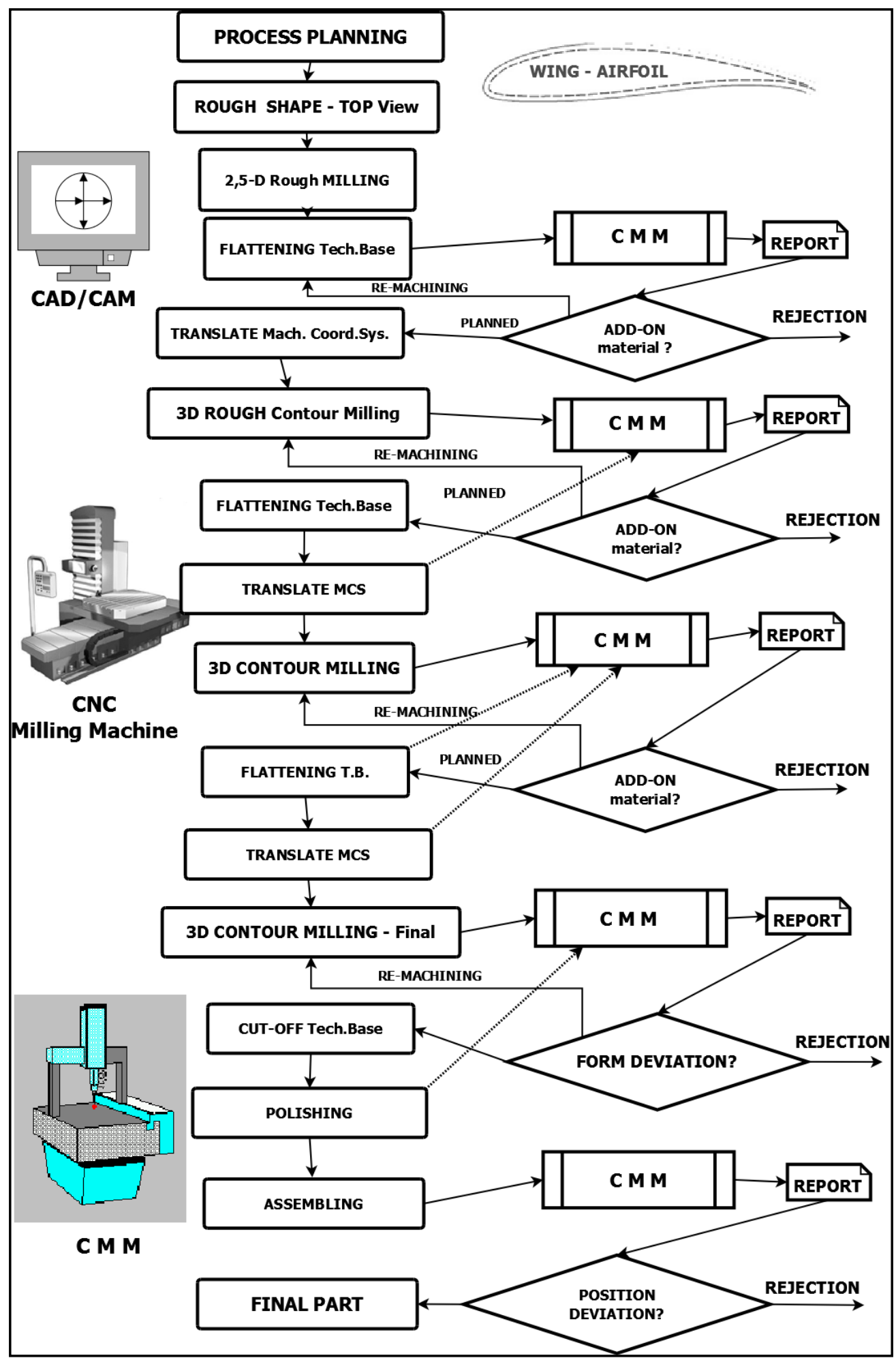

Figure 11. Wind tunnel models; flow chart of wing manufacturing process.

Measuring geometry of parts between machining operations is the one of the critical operation. It is necessary to have specialized developed measurement method. 
Flow chart of wing manufacturing process is shown in Figure 11 (Živković, 2013). There are a lot of "rejection" ways-out, but only one leads to wing requested quality. By constantly rotating and alternating machining of upper and lower surfaces of the wing, flattening of the technological base leads to work piece without residual stresses. It is necessary during machining process planning to introduce additional technological base mounts to reduce wing deflection. It is necessary to use milling machines with four and five axis of simultaneously motion. Preferably, the cut-off technological base executes on electro discharge machine with wire is necessary. Milling cutter "hits" the work piece, introducing additional stresses. After contour machining operation, there may be only polishing by the hand.

\section{Maximum Material Management}

Production quality control model of aircraft wings developed method provided the maximum material management (Živković, 2011). Critical activities in the technological process of making the wing are moving reference plane of machining. These displacements, after each operation, provide a uniform distribution of additives for machining operations that follow. Results coordinate inspection control sections are analyzed according to established criteria and determine the values and directions of moving reference plane of machining (see Figure 11). Established criteria in each phase of the airfoil to the measured deviations are within the scatter of the "six sigma". Such strict criteria decision making is set by the fact that the coordinate inspections performed a minimum number of points of the developed method. Methods presented in this section to minimize the time of preparation and execution of metrological task ensure achievement of planned quality model aircraft.

Figure 12 represents typical deviation diagram of measured airfoil (Majstorović \& Živković, 2013). Deviations measured/theoretical were magnified 100 times to make it easier to notice errors in manufacturing process. The diagram is created in Excel; it is not necessary that the user has specialized measurement programs for analyzing airfoil deviations.

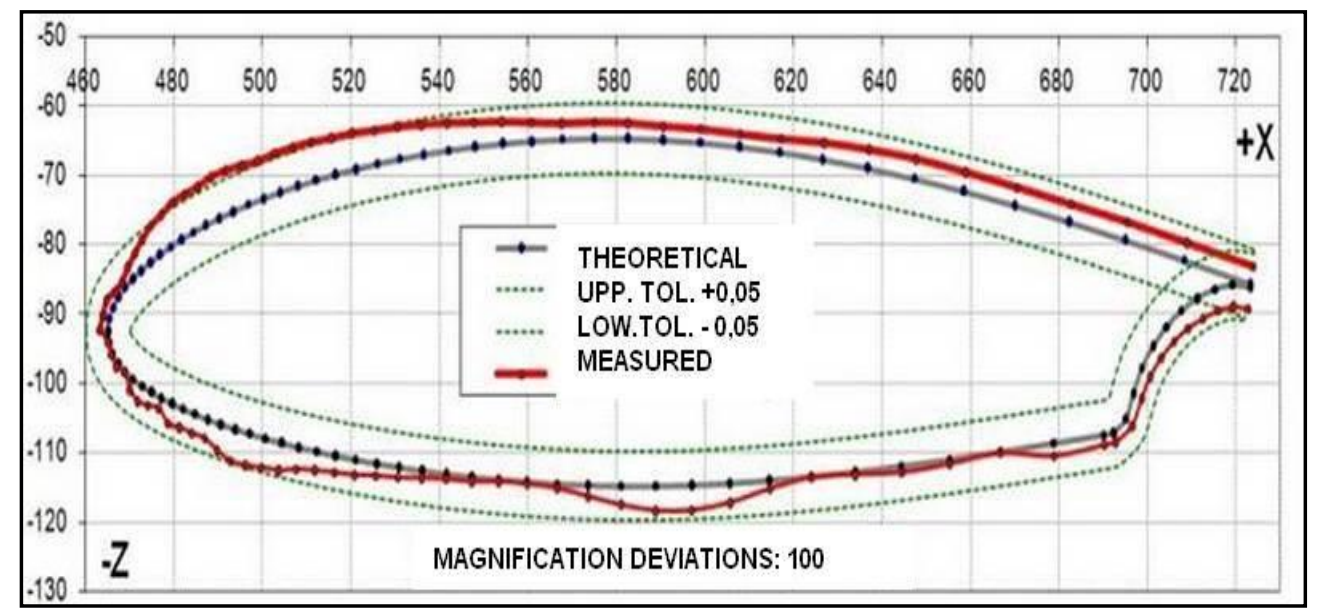

Figure 12. LASTA airplane; wind tunnel model (scaled $1: 5$ ); airfoil deviation (clean wing, no flaps); left wing, section position $210 \mathrm{~mm}$ parallel to CL (central line).

\section{Experimental Results}

The developed method is successfully applied in the department for design and production of model for wind tunnel testing in MTI Belgrade. The methods presented are crucial to quality management of production 
models for wind tunnel testing. These methods are applied after each machining operation as well as for the final identification of the quality parameters of the wind tunnel model.

The first step of implementation of these methods is the preparation on CAD/CAM system: the generation and distribution of points on the upper and lower surface of the wing. For each pair of points on the upper and lower side of the wing, dividing parameter $\lambda$ was calculated according to previous explained procedure. Theoretical coordinates of the generated points and the vectors normal of the local surfaces of the wing are transferred to coordinate inspection program.

The second step is the execution of coordinate measuring machine. CMM collects measured coordinates with the entire set of previously generated points. Form deviations for each wing section are given as a diagram shown in Figure 12. Position deviation, defined by wing setting angle and dihedral angle, is calculated over the entire set of measured points of the upper and lower surface of the wing using the equations (1)-(4).

Wind tunnel model of airplane LASTA, as shown in Figure 1, has measured setting angle $1.9873^{\circ}$ for right wing and $2.0127^{\circ}$ for left wing; theoretical value is $2^{\circ}$. Dihedral angle for left wing is $2.9533^{\circ}$ and $3.0297^{\circ}$ for right wing. These values are very close to theoretical value of $3^{\circ}$ and within a defined tolerance. Measured value of local twisting of airfoil on wing-tip section is $3.5831^{\circ}$; theoretical value is $3.5^{\circ}$. Results are shown in Figure 13.

Figure 14 presents the results of measurements of $10^{\circ}$ flap deflection, 2D-wing $1 \mathrm{~m}$ span. These tests are used to verify the performance of airfoil NACA $63_{2}-415$, which was used for wing design of the model shown in Figure 1. Due to the high slenderness, flap deflection is measured in three distinct zones: the left side of the wing and the right side of the wing and mid-wing area.

Each of the zones is measured on 20 points of on the upper side and 20 points on the lower surface of the flap. The small crosses in Figure 14 represent the measured point's chord plane, obtained by the method presented in this paper. The obtained values indicate that the deflection angles of the left and right ends differ by $0.1^{\circ}$, which is greater than the requested tolerance.

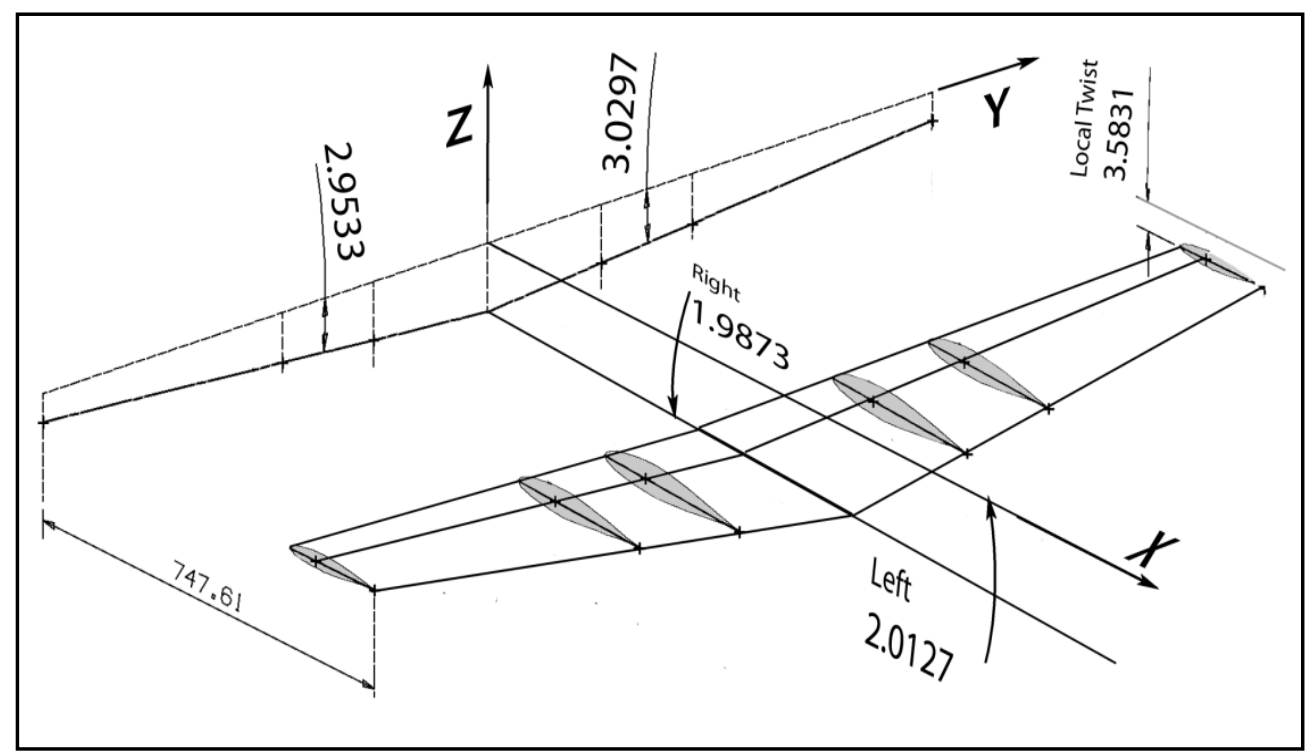

Figure 13. Measured dihedral and wing setting angle, wind tunnel model LASTA (model scale $1: 5$ ). 


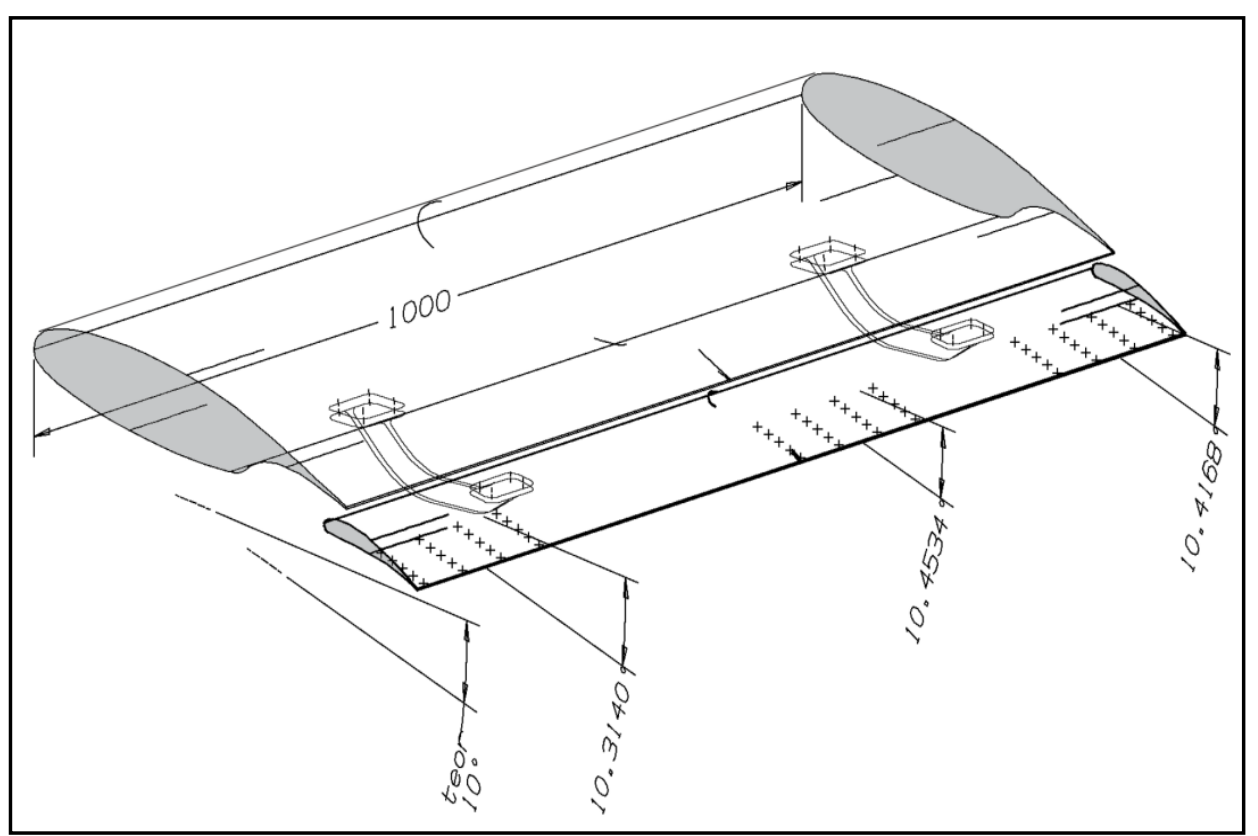

Figure 14. Measured flap deflection angle (theoretical $10^{\circ}$ ); 2D-wing, airfoil: NACA 63 ${ }_{2}-415$; span: 1,000 mm.

\section{Conclusions}

The presented method of WRP measurement was developed because commercial software packages for coordinate metrology are not able to fully meet the whole requirements of the wind tunnel model geometric inspection. Coordinate inspection is crucial for quality management of whole manufacturing process, as well as final confirmation of the quality and accuracy of the wind tunnel model. Set goals and objectives are achieved:

- identifying the critical activities that can be improved and optimized;

- defining method of determining the minimum number of points for airfoil inspection;

- defining a new settings method measuring coordinate system according to a wing;

- defining by the original method of measurement used to determine the WRP. The method is able to identify angles of deflections for control surfaces: flaps, slats, ailerons, and rudders;

- defining for a control method for maximum material during machining of lifting and control surfaces of aircraft models the basis on result of the coordinate inspections.

All developed and presented methods successfully are applied on several different international and domestic projects. The present paper is part of a larger study by Živković (2011), whose primary objective was quality management of manufacturing process, because accuracy of airfoil has a very large impact on the results of testing in the wind tunnel.

\section{References}

Abbott, I. A., \& Von Doenhoff, A. E. (1959). Theory of wing sections. New York, NY: Dover Publications.

Bak, C., Fuglsang, P., Johansen, J., \& Ioannis, A. (2000). Wind tunnel tests of the NACA 63-415 and a modified NACA 63-415 airfoil. Retrieved from www.risoe.dk/rispubl/vea/veapdf/ris-r-1193.pdf

Boon, D., Dwight, R., Sterenborg, J. J., \& Bijl, H. (2012). Uncertainties in a wind-tunnel experiment using Bayesian updating. Proceedings from 53rd AIAA/ASME/ASCE/AHS/ASC Structures, Structural Dynamics and Materials Conference, Hawaii, USA.

Bručas, D., \& Sužiedelyt-Visockien, J. (2010). Measuring surface geometry of airplane wing by means of two methods. Journal Aviation, 13(2), 44-49. 
Buck, G. M. (2000). Rapid model fabrication and testing for aerospace vehicles. Proceedings from AIAA 2000: 38th AIAA Aerospace Sciences Meeting \& Exhibit.

Buck, G. M., Powers, M. A., Griffith, M. S., Hopkins, J. W., Veneris, P. H., \& Kuykendoll, K. A. (2006). Fabrication of 0.0075-scale orbiter phosphor thermography test models for shuttle RTF aeroheating studies. Hampton, Virginia: Langley Research Center.

Chen, H., Wang, Q., \& Hu, R. (2011). Conditional sampling and experiment design for quantifying manufacturing error of transonic airfoil. Proceedings from AIAA 2011: 49th AIAA (American Institute of Aeronautics and Astronautics) Sciences Meeting, Orlando, USA.

Chen, Z. H., Du, F. Z., \& Tang, X. Q. (2013). Research on uncertainty in measurement assisted alignment in aircraft assembly. Chinese Journal of Aeronautics, 26(6), 1568-1576.

Faux, I. D., \& Pratt, M. J. (1979). Computational geometry for design and manufacture (Series: Mathematics and its applications). Chichester, England: Ellis Horwood Ltd.

Hepperle, M. (2014). MH 32: Some wind tunnel results (personal model aeronautics pages). Retrieved from http://www.mh-aerotools.de/airfoils/mh32exp.htm

Ichikawa, G., Kasai, K., \& Motogoe, S. (2008). Estimation of the influence of profile error on aerodynamic performance for low-Reynolds-number airfoils. Proceedings from ICAS 2008: 26th International Congress of the Aeronautical Sciences, Anchorage, USA.

Joseph, J. M., \& David, M. P. (1956). Design and construction of wind tunnel models (Report 20). Proceedings from AGARD (NATO Advisory Group for Aeronautical Research and Development): 8th Meeting of the Wind Tunnel and Model Testing Panel, Rome, Italy.

Lyon, C. A., Broeren, A. P., Giguere, P., Gopalarathnam, A., \& Selig, M. S. (1997). Summary of low-speed airfoil data Vol. 3. Virginia Beach: SoarTech Publications.

Majstorović, V., \& Hodolič, J. (1998). Numerički upravljane merne mašine (Coordinate measuring machines) (Faculty of Technical Science, Institute for production engineering, Novi Sad Serbia).

Majstorović, V., \& Živković, S. (2013). Developed computer aided inspection method for free-form surfaces applied on aeronautical lift and control surfaces. Proceedings from IMEKO 2013: 11th International Symposium on Measurement and Quality Control, Cracow-Kielce, Poland.

Rendulić, Z. (1962). Mehanika leta (Flight mechanics). Belgrade, Serbia: Komanda RV i PVO.

Savio, E., De Chiffre, L., \& Schmitt, R. (2007). Metrology of freeform shaped parts. Annals of the CIRP, 56(2), 810-835.

Selig, M. S., Guglielmo, J. J., Broeren, A. P., \& Giguere, P. (1995). Summary of low-speed airfoil data Vol. 1. Virginia Beach: SoarTech Publications.

Selig, M. S., Lyon, C. A., Giguere, P., Ninham, C. N., \& Guglielmo, J. J. (1996). Summary of low-speed airfoil data Vol. 2. Virginia Beach: SoarTech Publications.

Zilker, A., \& Winter, D. (1999). WinGS: Optical measurement and inspection system for aircraft wind tunnel models. Proceedings from SPIE 3824: Optical Measurement Systems for Industrial Inspection, Munich, Germany.

Živković, S. (2011). Optimizacija merenja složenih prostornih oblika metodama koordinatne metrologije (Optimization of free form surfaces measuring using coordinate metrology methods) (Engineering doctorate, Military Academy Belgrade).

Živković, S. (2013). Quality management aeronautical surfaces manufacturing. Proceedings from IWC-TQM 2013: 7th International Working Conference "Total Quality Management-Advanced and Intelligent Approaches", Mechanical Engineering Faculty, Belgrade, Serbia. 